\title{
Measuring intra-generational redistribution in PAYG pension schemes
}

\author{
Jonas $\mathrm{Klos}^{1} \cdot \operatorname{Tim}_{\mathrm{Krieger}}^{2,3}$ (D) $\cdot$ Sven Stöwhase ${ }^{4}$
}

Received: 5 October 2020 / Accepted: 14 June 2021 / Published online: 3 July 2021

(c) The Author(s) 2021

\begin{abstract}
Voters in ageing societies expect pension reforms to be both inter-generationally and intragenerationally fair. In this paper, we propose a global measure of intra-generational redistribution in pay-as-you-go pension schemes as a basis for voters' evaluations of reforms. Our novel index only requires information on contributions by and pension benefits paid to retirees, enabling us to measure intra-generational redistribution isolated from possible inter-generational redistribution. We rely on the contribution records of approximately 100,000 Germans, who progressed into retirement in 2007-2015, to measure the level of intra-generational redistribution in the German statutory pension scheme (GRV). A recent reform of the childcare benefit provision, which became effective in 2014, confirms the predictions of our index. The reform introduced additional benefits for a substantial subgroup of German mothers, owing to which the index value for women, but not for men, jumps up. Our findings suggests that GRV fulfills the ideal of a Bismarckian pension system without intra-generational redistribution for men, while women benefit significantly from intra-generational redistribution.
\end{abstract}

Keywords PAYG pension systems · Political support for reform · Intra-generational redistribution $\cdot$ Beveridge versus Bismarck $\cdot$ Index $\cdot$ Micro-data $\cdot$ Germany

JEL Classification H55 · D31 · C55

Tim Krieger

tim.krieger@vwl.uni-freiburg.de

Jonas Klos

jonas.klos@brh.bund.de

Sven Stöwhase

sven.stoewhase@ fit.fraunhofer.de

1 Bundesrechnungshof (German Supreme Audit Institution), Adenauerallee 81, 53113 Bonn, Germany

2 Department of Economics, University of Freiburg, Wilhelmstr. 1b, 79085 Freiburg i. Br., Germany

3 CESifo, Munich, Germany

4 Microsimulation and Econometric Data Analysis, Fraunhofer FIT, Schloss Birlinghoven, 53754 Sankt Augustin, Germany 


\section{Introduction}

Demographic change and the ageing of societies have become major challenges to industrialized countries. Pension reforms, especially in the first pay-as-you-go (PAYG) financed public pillar of pension schemes, therefore will be unavoidable, but need to be backed by public acceptance and, ultimately, democratic support. Arguably, such support is stronger when pension reforms appear acceptable along two dimensions.

First, the reforms need to balance the interests of the involved living, and possibly also yet unborn, generations, i.e., after a reform the pension system must still be seen as broadly inter-generationally fair. ${ }^{1}$ Second, public pension systems usually are considered to be part of the broader public tax-transfer mechanism. Although controversial, the public and many politicians expect public pension systems to also redistribute intra-generationally, i.e., between different types of households of the same generation.

Our paper aims at providing new insights into the second type of redistribution, i.e., the relevance of intra-generational redistribution and the effects that even minor parametric reforms might have on it. More specifically, intra-generational redistribution refers to situations in which pension policies, e.g., through child-rearing benefits, induce a more equal distribution of pension benefits than the distribution of previous own contributions to the pension system.

We contribute to the existing literature in a threefold manner. First, we develop a novel global measure for intra-generational redistribution in PAYG pension schemes wherein redistribution results from specific pension policies applying to the acquisition of pension entitlements during work life. ${ }^{2}$ Our index, which is reminiscent of the Suits index for tax progression (Suits, 1977), describes the actual policy design at any given point in time and can accentuate the effects of policy changes. It relates work-life contributions to the pension scheme and the resulting benefit entitlements to a benchmark, which rests on the ratio of two hypothetical benefit distributions resulting from idealized pension systems, one with flat benefits and one with earnings-proportional benefits. Second, we resolve several theoretical and empirical shortcomings of existing measures of intra-generational redistribution. Third, we apply our index to micro-level data from the German public pension system (Gesetzliche Rentenversicherung, GRV) and a recent reform of the childcare benefit provision in order to highlight the resulting and substantial effects.

Our paper starts from the presumption that for rational individuals and voters, the evaluation of pension policies (which may affect intra-generational redistribution) depends on how these policies change the rate of return on their contributions to the PAYG pension system. Here, the link between one's own contributions and benefits and whether it is more or less direct matters most. Let us consider two polar cases. In the first case of a Bismarckian pension system (cf. Casamatta et al., 2000a, 2000b; Cremer \& Pestieau, 2003), benefits are earnings-related with full proportionality between earnings (and thus earnings-related contributions) during work life and paid-out pension benefits after retirement. The other polar case assumes no link at all between earnings and benefits, which typically is achieved

\footnotetext{
1 While potential generational conflict is a topic of public debate and academic discourse, the existing empirical evidence in its favor is not overly robust (for a summary of evidence cf., e.g., Krieger \& Ruhose, 2013).

${ }^{2}$ It should be noted that we focus only on redistributive elements within the pension system. We do not consider other parts of the tax-transfer system, through which the effects that we predict and measure could be strengthened or weakened, such as the (progressive) taxation of paid-out pensions benefits.
} 
by having flat benefits for each member of the pension scheme, regardless of one's personal contributions or income tax payments (pension schemes of this type-so-called Beveridgean pension systems-often are tax-financed). ${ }^{3}$

Most real-world pension schemes are somewhere in between those extremes. That is because of the observation that the majority of voters prefer some redistribution among members of the same generation even in traditional Bismarckian pension schemes. Table 1 provides an overview of non-earnings-related benefits in the German public pension system, ${ }^{4}$ which was introduced by Reich Chancellor Otto von Bismarck in 1889 as the prototype Bismarckian pension system with a fully proportional earnings-benefit link. That link has weakened over time because of, among other things, benefits based on time spent childrearing, when mothers receive benefits as if they were working, although they do not. Benefits of that type play a significant role in today's German pension system.

Previous studies (Börsch-Supan \& Reil-Held, 2001; Krieger \& Traub, 2008, 2011, 2013; Lefèbvre, 2007; Lefèbvre \& Pestieau, 2006; OECD, 2013; Stöwhase, 2016) have proposed theoretical measures of intra-generational redistribution that-in one way or the other-make use of the idea of quantifying the share of non-earnings-related benefits in total benefits. However, those measures are difficult to apply empirically because of their restrictive assumptions. ${ }^{5}$ Our novel measure of intra-generational redistribution in pension systems works in a similar direction but avoids the problems of existing measures. It does so by relating work-life pension contributions and benefit entitlements to a benchmark that rests on the ratio of idealized Beveridgean and Bismarckian benefit distributions. The construction of our measure follows broadly the construction of Lorenz curves and the Gini coefficient and resembles measures of inequality in tax systems, such as the Suits index (Suits, 1977). The method leads to a more general representation of intra-generational redistribution than do existing measures, which also facilitates empirical applications. This allows us to make use of a rich dataset on individual earnings histories of approximately 100,000 individual Germans, who progressed to retirement in 2007-2015, and to measure intra-generational redistribution in the GRV and test the robustness of our measure.

To preview our main empirical findings, a recent reform of the childcare benefit provision, which became effective in 2014 and introduced additional benefits for a subgroup of German mothers, caused our index value to jump up for women, but not for men. Our findings suggest that the GRV fulfills the ideal of a Bismarckian pension system without intra-generational redistribution for men, while women benefit substantially from intragenerational redistribution.

Our paper is structured as follows. Section 2 discusses existing measures of intragenerational redistribution and their limitations. Furthermore, we derive our index in this

\footnotetext{
${ }^{3}$ Owing to the larger degree of redistribution, Beveridgean pension schemes typically are smaller (less generous) in absolute terms than Bismarckian pension schemes (Conde-Ruiz \& Profeta, 2007).

4 We present information on the German pension system here because the empirical analysis in our paper will refer to that very system.

${ }^{5}$ For instance, Krieger and Traub (2011) rely on the Luxembourg Income Study (LIS), which is a collection of independently sampled waves, for comparisons of the distributions of incomes and retirement benefits. LIS data do not come, however, as a panel, which implies that one cannot derive individual earnings histories from that dataset. Therefore, the authors have to assume that the income distribution does not change from generation to generation in order to be able to compare different generations (i.e., workers and retirees) within a wave. As we will show in the next section of our paper, all existing measures of intragenerational redistribution suffer from similar critical assumptions. Note that the experimental design in Krieger et al. (2020) avoids the difficulties experienced in empirical work.
} 
section. The following Sect. 3 presents the empirical application of our index to the German pension system using micro-data on German retirees. Section 4 concludes.

\section{Measuring intra-generational redistribution}

\subsection{Existing measures of intra-generational redistribution}

The focus of our paper is on measuring intra-generational redistribution resulting from pension system design and parametric policy changes. The respective design and policy variables may affect the acquisition of pension entitlements during work life; they usually will become effective after entering retirement, when one starts to receive pension benefits. That feature could, for instance, be entitlements to benefits granted for rearing children. In that case, a working-age person-usually, the mother-does not work and herefore does not pay contributions into the pension system. To compensate for financial disadvantages during later retirement because of shorter contribution times, pension entitlements are granted that do not relate to wage income but rather time spent child-rearing.

Another dimension of intra-generational redistribution occurs more naturally whenever annuities are relied on to insure against longevity risk. This redistribution is driven by systematic differentials in life expectancy, as they exist between, e.g., educated and less educated people with higher and lower incomes, respectively (Cutler et al., 2006; Marmot, 2005; Waldron, 2013). Additional educational achievement correlates not only with a longer life but also with a longer time of receiving pension benefits, implying regressivity of the pension system (e.g., Brown et al., 2006; Coronado et al., 2011; Goda et al., 2011). Some debate exists about whether welfare gains through reduced regressivity could be achieved by fundamental reforms of the benefit formula (e.g., Bagchi, 2019; Bishnu et al., 2019; Bommier et al., 2011; Krieger et al., 2020); one prominent example being the Boskin proposal for the United States that recommends separating US Social Security into insurance and transfer components (Boskin, 1986). ${ }^{6}$ Given our focus on policies implemented during work life and through changes in entitlement provisions, we will not consider policies along those lines here.

Rather, we will resort to a strand of the literature that provides specific measures of intra-generational redistribution that can be employed to study parametric policy changes affecting the acquisition of entitlements during work life. Those measures allow for comparisons either over time or between countries, and sometimes also between specific subgroups of a population. In the following, we will introduce the most important indices and discuss their properties. ${ }^{7}$

The index of non-contributiveness (INC) introduced by Lefèbvre and Pestieau (2006) and Lefèbvre (2007), here denoted by $\beta^{I N C}$, is defined as the ratio of the income share of public pensions in the bottom income quintile, $B$, to the same share in the top quintile, $T$ :

\footnotetext{
${ }^{6}$ Further work in this strand of the literature deal with the effects of privatizing US Social Security; e.g., Auerbach \& Kotlikoff, 1987; Kotlikoff, 1998; Kotlikoff et al., 1999.

7 Note that one particularly simple approach would be to identify all benefit payments that are not backed by contribution payments (such as the ones in Table 1), add them up, and relate them to total benefits (as in, e.g., Börsch-Supan \& Reil-Held, 2001). However, the main downside of that approach is that not all benefits can be identified clearly as not being backed by contributions.
} 
Table 1 Non-earnings-related benefits in the German pension system (GRV)

Type of benefits

Benefits due to early retirement

Benefits without contributions due to education, unemployment, illness, and other work-related circumstances

Benefits due to child raising

Benefits payable to repatriates/foreigners resident in Germany under special conditions

Higher evaluation of vocational periods

Health/long-term care insurance for pensioners

Minimum pension

Invalidity pension

Part-time work for older workers

$$
\beta^{I N C}:=\frac{P_{B} / Y_{B}}{P_{T} / Y_{T}}=\frac{P_{B}}{P_{T}} \cdot \frac{Y_{T}}{Y_{B}},
$$

where $Y_{i}$ and $P_{i}, i \in\{B, 2,3,4, T\}$, are the mean income and the mean pension benefit, respectively, of the $i$ th quintile of the income distribution. A pure Beveridgean pension system with equal benefits for all retirees implies $\frac{P_{B}}{P_{T}}=1$ and, hence, $\beta=\frac{Y_{T}}{Y_{B}} \geq 1$. A pure Bismarckian system that relates benefits solely to previous earnings would yield $\frac{P_{B}}{Y_{B}}=\frac{P_{T}}{Y_{T}}$ and therefore $\beta=1$. Although it is possible to normalize that measure to fit into the $[0,1]$ interval (cf. Krieger \& Traub, 2011, 2013), ${ }^{8}$ some obvious disadvantages arise for the measurement of intra-generational redistribution.

First, considering only the ratio between the top quintile and the bottom quintile of the income distribution, potentially one loses important information contained in the complete income distribution. ${ }^{9}$ Second, the INC compares two entirely different generations with each other, the working population and the pensioners, thereby implicitly assuming that the income distribution does not change from generation to generation. The same needs to be assumed for any redistributive measures introduced by governments at different times. Clearly, neither can be taken for granted. A suitable measure should rather compare the benefits of current retirees with their previous contributions, which then includes

\footnotetext{
${ }^{8}$ Following Casamatta et al. (2000a), Krieger and Traub $(2011,2013)$, assume that retirees' incomes are a linear combination of a flat and an earnings-dependent component: $P_{i}=\tau \bullet\left(\alpha Y_{i}+(1-\alpha) \mu\right)$, where $\alpha \in[0,1]$ is the Bismarckian factor, $\mu=\sum_{i} Y_{i} / 5$ the average income of the entire income distribution, and $\tau$ a measure of the generosity of the pension system (i.e., a measure of income replacement and inter-generational redistribution). Here, the Bismarckian factor is the relevant measure of intra-generational redistribution: $\alpha=\frac{\left(P_{T}-P_{B}\right) \mu}{\left(P_{T}-P_{B}\right) \mu-P_{T} Y_{B}+P_{B} Y_{T}} \in[0,1]$. A pure Beveridgean pension system $\left(P_{B}=P_{T}\right)$ leads to $\alpha^{B e v}=0$, a pure Bismarckian system $\left(P_{B} / Y_{B}=P_{T} / Y_{T}\right)$ to $\alpha^{B i s}=1$.

${ }^{9}$ For instance, if pension benefits are calculated differently at different income levels, INC will be biased. Consider a Bismarckian pension scheme that covers the middle class only, i.e., there is a tight link between earnings and benefits in the second, third, and fourth quintile, while at the bottom and the top of the distribution only a flat minimum benefit is received. Then, $\beta^{I N C}>1$ since $P_{B} / P_{T}=1$. For the middle-class members of the scheme (ignoring the third quintile for simplicity), we have $\beta_{2,4}^{I N C}=1$ since $P_{2} / P_{4}=Y_{2} / Y_{4}$. Hence, since $\beta^{I N C}>\beta_{2,4}^{I N C}=1$, the $I N C$ based on $B$ and $T$ only obviously lacks complete information.
} 
intra-generationally redistributive policies during work life. ${ }^{10}$ Therefore, it is preferable to consider individual contributions and benefits at the micro level.

The index of progressivity $(I O P)$ as applied by the OECD in its publications on pension politics (OECD, 2013) resolves the first, but not the second disadvantage. IOP, here denoted by $\gamma^{I O P}$, relates inequality in pension benefits to inequality in earnings:

$$
\gamma^{I O P}:=1-\frac{G_{P}}{G_{Y}}
$$

where $G_{P}=\frac{1}{2} \bar{P} n^{2} \sum_{\mathrm{i}=1}^{n} \sum_{\mathrm{j}=1}^{n}\left(P_{i}-P_{j}\right)$ and $G_{Y}=\frac{1}{2} \bar{Y} m^{2} \sum_{\mathrm{k}=1}^{m} \sum_{\mathrm{l}=1}^{m}\left(Y_{k}-Y_{l}\right)$ are the Gini coefficients of pensions and earnings, respectively, $\bar{P}$ and $\bar{Y}$ are mean pensions and mean earnings, $n$ is the number of pensioners, and $m$ the number of employees. In a pure Bismarckian pension scheme, $\gamma^{I O P}=0$ since $G_{P}=G_{Y}$. In contrast, in a Beveridgean scheme, $\gamma^{I O P}=1$ because $G_{P}=0$. Compared to INC, the IOP makes use of the complete distribution of both pension benefits and earnings. However, this measure still relates current pensions to current earnings without linking individuals' contributions and pension entitlements.

If information on both contributions $c_{i}$ and pension entitlements $p_{i}$ is available for all individuals $i, i=1, \ldots, N$, a simple alternative to the above measures is a correlation analysis. Stöwhase (2016) calculates the coefficient of correlation of a contribution vector $C=\left\{c_{1}, c_{2}, \cdots, c_{n}\right\}$ and a benefit vector $P=\left\{p_{1}, p_{2}, \cdots, p_{n}\right\}$ for all $N$ pensioners. While it is straightforward that a pure Bismarckian system implies $\operatorname{Corr}(C, P)=1$, a measure that is exclusively based on this correlation suffers from the problem that it cannot be normalized. This is because in a Beveridgean pension scheme, its value would depend on the distribution of pension benefits $P$, which is not accounted for. Hence, any $\operatorname{Corr}(C, P) \neq 1$ is hard to interpret. However, the measure of correlation could be a good starting point for developing a new measure of intra-generational redistribution if normalization is possible.

\subsection{Introducing a novel global measure of intra-generational redistribution}

In order to overcome the problems of existing measures of intra-generational redistribution in PAYG pension systems, we propose a novel index that relates paid contributions to resulting benefits. Analogous approaches can be found in the literature on inequality and the progressiveness of tax systems. Lambert and Ramos (1997) present a general index of horizontal inequity in income taxes that measures the inequality of post-tax incomes for pre-tax equals. In a similar vein, Suits (1977) proposes an index, the so-called Suits index, to measure tax progressivity by relating accumulated incomes to accumulated tax burdens. This is reminiscent of the Gini ratio. Our index follows along similar lines: it provides a standardized global measure of intra-generational redistribution by relating contributions and the resulting entitlements to a benchmark, which rests on the ratio of the (hypothetical) distributions of ideal Bismarckian and Beveridgean pension schemes.

Like Suits (1977) and Lambert and Ramos (1997), our index is a global measure of redistribution. Compared to local measures of redistribution, global measures make use of

\footnotetext{
${ }^{10}$ Note that this does not take into consideration any kinds of redistribution between different groups of retirees, such as redistribution via the tax system between rich and poor retirees, or more complex forms of redistribution following from differences in life expectancy (cf., e.g., to the discussion in Krieger \& Lange, 2012).
} 
the entire income distribution rather than just parts of it. As Seidl et al. (2012, p. 25) point out, this has certain advantages; for example, global measures allow for an ordering of the (intra-generational) redistributiveness of pension systems and, thus, for international and intertemporal comparisons. Furthermore, they respond appropriately to changes in weighting along the income distribution, e.g., when a specific group of beneficiaries grows. However, the ability to aggregate the effects of redistributive schemes over the whole support of the income distribution comes as a double-edged sword, because global measures of redistribution may obscure opposing effects occurring in different parts of the income distribution. In addition, the aggregation procedure needed to derive the measure presupposes comparability of benefits independent of personal income. ${ }^{11}$

Let us start by assuming a population consisting of two groups at time $t: N$ retirees, indexed and ordered by $i \in\{1,2, \ldots, N\}$, and $K$ working-age contributors, indexed and ordered according to paid contributions by $j \in\{1,2, \ldots, K\}$. Until her retirement, each individual $i$ has paid amount $e_{i}$ into the pension scheme. This contribution payment in any period $t$ is given by ${ }^{12}$ :

$$
e_{i}=\sum_{l=1}^{m} h\left(Y_{l}^{i} \lambda_{l}\right), \quad m \leq t,
$$

with $m$ representing the time of retirement, $Y$ representing personal income and thus the contribution assessment basis, and $\lambda$ being the contribution rate that had to be paid in each period of work life. ${ }^{13}$ Function $h(\cdot)$ adjusts each period's paid contributions according to the rules of the present pension system. For instance, in the German GRV, which we will refer to in our empirical analysis in Sect. 3, paid contributions are transformed into socalled earnings points following the specific rules of GRV. ${ }^{14}$ Other functional forms may, e.g., include a binary component counting only best (rather than $\mathrm{all}$ ) contribution years. ${ }^{15}$

The sum of contributions $e_{i}$ of each individual $i$ represents the basis for calculating the personal pension entitlement $P E_{i}$. This entitlement defines the actual amount of pensions paid out to $i$. Using (3), we can define entitlements for members of both the Beveridgean or the Bismarckian pension system at time $t$ :

$$
\text { Beveridge : } \quad P E_{i}^{B e v}=\frac{\sum_{i=1}^{N} e_{i}}{N} \delta,
$$

Beveridge : $\quad P E_{i}^{B i s}=e_{i} \delta$,

\footnotetext{
11 These disadvantages led to the development of another class of tax progressivity or redistribution measures that use dominance relations: measures of uniform tax progression or redistribution (for details of the measures, see Seidl et al., 2012, chapter 4).

12 For easier notation, we will skip the time index in the following. Any equation will always refer to the current period $t$.

13 Note that $m \leq t$ ensures that the individual has retired in the past or in the most recent period $t$. That is, we consider current pensioners only at this stage.

14 Points systems also exist in Estonia, France (occupational plans), Lithuania, and the Slovak Republic (OECD, 2019).

15 Only comparatively small fractions of career earnings are considered in, e.g., France (main scheme, best 25 years), Slovenia (24), and Spain (25) (OECD, 2019).
} 
where $P E_{i}$ represents the pension entitlement of individual $i$ and $\delta$ is a measure of generosity which indicates how contributions $e_{i}$ are valued. More generally speaking, the generosity measure indicates the level of redistribution between generations (Krieger $\&$ Traub, 2011, 2013). It depends on the development of societal key indicators like income or demography in the long run, while it is often decided upon by legislators in the short run (thereby ignoring - in a non-sustainable manner-their decision's long-run implications; cf., e.g., Browning, 1975; Sjoblom, 1985).

Inter- and intra-generational redistribution are intentionally separated here for a number of reasons. The two types of redistribution affect different groups in society differently. While changes in the inter-generationally redistributive features of a pension system affect mostly future generations (especially when reforms are phased in slowly, often over several decades), changes in design parameters related to intra-generational redistribution typically have immediate effects on voters. Our political-economic analysis is therefore particularly interested in providing an undisturbed look at the second effect. In fact, the political processes determining pension reforms along these lines differ substantially as well. While changes in inter-generational redistribution are major reforms involving extensive public debate, reforms of intra-generational redistribution are often parametric and used to fulfill requests by important but small voter groups. Finally, there is a pragmatic reason: We apply our index to the German pension system in the following empirical analysis; as Sect. 3.1 reveals, the German pension formula allows us to separate inter- and intra-generational redistribution, and so do the data we use. Note that for the sake of convenience, we assume that $\delta$ is time-invariant, although there is usually a slight increase over time.

Equation (4) represents an idealized Beveridgean pension scheme, in which the total sum of contributions made by all $N$ contributors is evenly split, awarding each individual the same entitlement regardless of her individual contribution $e_{i}$. Equation (5) is designed as an idealized Bismarckian system, where each individual's pension entitlement depends solely on her own past contributions.

Next, let us define the actual pension system:

$$
\begin{gathered}
P E_{i}^{P S}=G\left(e_{i}, x_{i}\right) \delta, \\
\delta \sum_{i=1}^{N} G_{t}\left(e_{i}, x_{i}\right)=\sum_{j=1}^{K} Y_{t}^{j} \lambda_{t}+S G_{t} .
\end{gathered}
$$

Equation (6) represents how personal entitlements are calculated in the actual pension scheme. The individual pension entitlement depends on own contributions $e_{i}$ as well as other individual factors $x_{i}$. How these factors are valued depends on the actual (redistributive) design of the pension scheme represented by function $G(\cdot)$. Note that in order to avoid issues of re-ranking (Jenkins, 1988), we assume co-monotonicity of contributions and pensions here. ${ }^{16}$ Equation (7) is the budget constraint of the pension scheme. The sum of pension entitlements is funded by the sum of contribution payments of all contributors and (possibly) a state grant $S G$ that subsidizes the pension scheme.

Equations (6) and (7) indicate legislators' various options for modifications, or reforms, of the pension scheme: the state grant and the contribution rate could be adjusted; the contribution assessment basis could be changed; the group of contributors could be adjusted;

${ }^{16}$ In the empirical part of our paper, we show that the possibility of re-ranking does not affect our findings. 
or the generosity $\delta$ could be changed. ${ }^{17}$ However, these options only affect inter-generational redistribution. Regarding intra-generational redistribution, legislators only have the option to modify function $G(\cdot)$. For instance, the importance of own contributions $e$ in determining pension entitlements could be shifted relative to the influence of individual factors $x$. This will change the degree of intra-generational redistribution for the current group of retirees.

The fact that intra-generational redistribution is affected only through the parameters in $G(\cdot)$ allows us to simplify our setting substantially. We can drop Eq. (7), in which all variables related to the degree of inter-generational redistribution are collected and which affect $G(\cdot)$ only in terms of level shifts. Hence, we can measure intra-generational redistribution based exclusively on information regarding contributions and individual factors as well as the functional form of $G(\cdot)$. Closer inspection of Eqs. (4)-(6), which are the only ones needed for our analysis, shows that this is indeed the case. Legislators using the presented framework to plan an adjustment of the rate of intra-generational redistribution via $G(\cdot)$ will of course have to take the budget constraint of Eq. (7) into account. However, for the purpose of our index, this constraint can be neglected.

Analogously to the methodology of the Suits index, let us now order and normalize the distribution of $e$ on the interval $[0,1]$, such that it measures the accumulated share of paid contributions. Furthermore, we define $F_{P E}(e)$ as the cumulative distribution function of $P E$ depending on $e$ and the corresponding density function (or Suits curve) as $f_{P E}(e) .{ }^{18}$ At any point $e, F_{P E}(e)$ measures the accumulated sum of pension benefits in the sample population. Since we are only interested in the distribution of $e$ in Eqs. (4)-(6), we can also drop the constant generosity measure $\delta$.

This yields the following equations for the distributions of pension benefits in the actual and the two idealized pension systems:

$$
\begin{gathered}
\text { Beveridge : } F_{P E}^{B e v}(E)=\int_{0}^{E} f_{P E}^{B e v}(e) d e:=\operatorname{Bev}(e), \\
\text { Bismarck : } F_{P E}^{B i s}(E)=\int_{0}^{E} f_{P E}^{B i s}(e) d e=\frac{1}{2} e^{2}:=\operatorname{Bis}(e), \\
\text { Actual pension system : } F_{P E}^{P S}(E)=\int_{0}^{E} f_{P E}^{P S}(e) d e:=P S(e) .
\end{gathered}
$$

Accordingly, $\operatorname{Bev}(e), \operatorname{Bis}(e)$, and $P S(e)$ represent the areas below the respective density functions or Suits curves of the ideal Beveridgean, ideal Bismarckian, and the real pension

\footnotetext{
${ }_{17}$ See e.g. Krieger and Stöwhase (2009) for the effects of discrete policy interventions on the generosity of the German pension scheme.

${ }^{18}$ Note that one could also derive this density function from the first-order moment function of pension benefits $F_{P E}(E)=1 / \bar{e} \int_{e}^{E} G(e) f(e) d e$ (where $e \in\left[e_{\min }, e_{\max }\right]$ and $\bar{e}$ denotes the mean contribution) by replacing $E$ with the inverse of the distribution function of entitlements $F_{P E}^{-1}(e)$, where $e \in[0,1]$ as required.
} 
system on the interval $[0, e]{ }^{19}$ where (as can be seen in Fig. 1) $\operatorname{Bis}(1)=0.5$ is the area below the diagonal. Our index of intra-generational redistribution is then defined as

$$
R:=\frac{\operatorname{PS}(\mathrm{e})-\mathrm{Bis}(\mathrm{e})}{\operatorname{Bev}(\mathrm{e})-\operatorname{Bis}(\mathrm{e})}=\frac{\operatorname{PS}(1)-0.5}{\operatorname{Bev}(1)-0.5}
$$

Equation (11) measures intra-generational redistribution by calculating how strongly the underlying pension system is trending towards one of the two benchmark distributions. Since these benchmarks are constructed by using the contributions of the underlying sample population, this trending is measured relative to the difference between the two benchmarks, as expressed by the denominator of $R$, which provides a standardization.

As stated above, this index is closely related to measures of inequality and progressiveness in tax systems that themselves are related to more general measures of inequality, in particular Lorenz curves and the Gini coefficient. Those measures should generally satisfy four main criteria, namely, scale or mean independence, symmetry, transfer sensitivity, and decomposability. In the following, we will discuss briefly whether these criteria also apply to our index.

Index $R$ satisfies the condition of scale or mean independence. If all individual contributions and pension entitlements were doubled, $R$ remains unchanged. The applied normalization ensures that $R$ does not depend on the size of the retiree population, meaning that $N$ has no direct effect on $R$. The order of individuals depends solely on contributions, which satisfies the criterion of symmetry. The transfer of pension entitlements from retirees with high contributions to those with lower contributions increases the index, meaning that $R$ moves towards the Beveridgean benchmark of fully equalized benefits. Therefore, the index also satisfies the Pigou-Dalton criterion of transfer sensitivity.

Another desirable feature of an inequality measure is decomposability, meaning that the total inequality of a population can be broken down into a weighted average of the inequality existing within subgroups of the population and the inequality existing between them. While it is possible to measure pension entitlements based on the contributions made by any arbitrarily chosen subgroup of retirees, the sum of index values for different subgroups does not yield the index value of the entire population. Hence, our inequality measure is not decomposable.

Importantly, while our index yields 0 for the Bismarckian or 1 for the Beveridgean benchmark, it is not confined to this range. For example, pension systems that are more restrictive than an idealized Bismarck system (e.g., if they redistribute regressively) would yield a negative index value. It is also possible, that $P S(e)$ intersects $B i s(e)$ (this could happen even more than once). In this case, the calculation may result in $\operatorname{PS}(e)=\operatorname{Bis}(e)$ and an index value of 0 despite redistribution occurring. As in the case of intersecting Lorenz curves, a possible solution would be to subdivide the sample population at the intersections and calculate index values for the resulting subsamples.

\footnotetext{
${ }^{19}$ For discrete data, Eqs. (8)-(10) can be calculated as follows: Individuals are ordered with respect to their own contributions. Then normalization is achieved by expressing $e_{i}$ as the respective share of all own contributions $\sum_{i=1}^{N} e_{i}$ and accumulating them. Therefore, at point $e=0.4$ we would have the lowest $40 \%$ of own contributions. This step is repeated for pension entitlements to derive the sums of pension entitlements $P E_{B e v}(e), P E_{B i s}(e)$, and $P E_{P S}(e)$. For instance, $P E_{P S}(0.4)=0.5$ means that the individuals with the lowest $40 \%$ of own contributions receive $50 \%$ of all pension entitlements. Equation (10) can then be approximated by $\sum_{i=1}^{N} \frac{P E_{P S}\left(e_{i-1}\right)+P E_{P S}\left(e_{i}\right)}{2}\left(e_{i}-e_{i-1}\right)$, and Eqs. (8) and (9) by $\sum_{i=1}^{N} \frac{P E_{B e v}\left(e_{i-1}\right)+P E_{B e v}\left(e_{i}\right)}{2}\left(e_{i}-e_{i-1}\right)$ and $\sum_{i=1}^{N} \frac{P E_{B i s}\left(e_{i-1}\right)+P E_{B i s}\left(e_{i}\right)}{2}\left(e_{i}-e_{i-1}\right)$, respectively,
} 


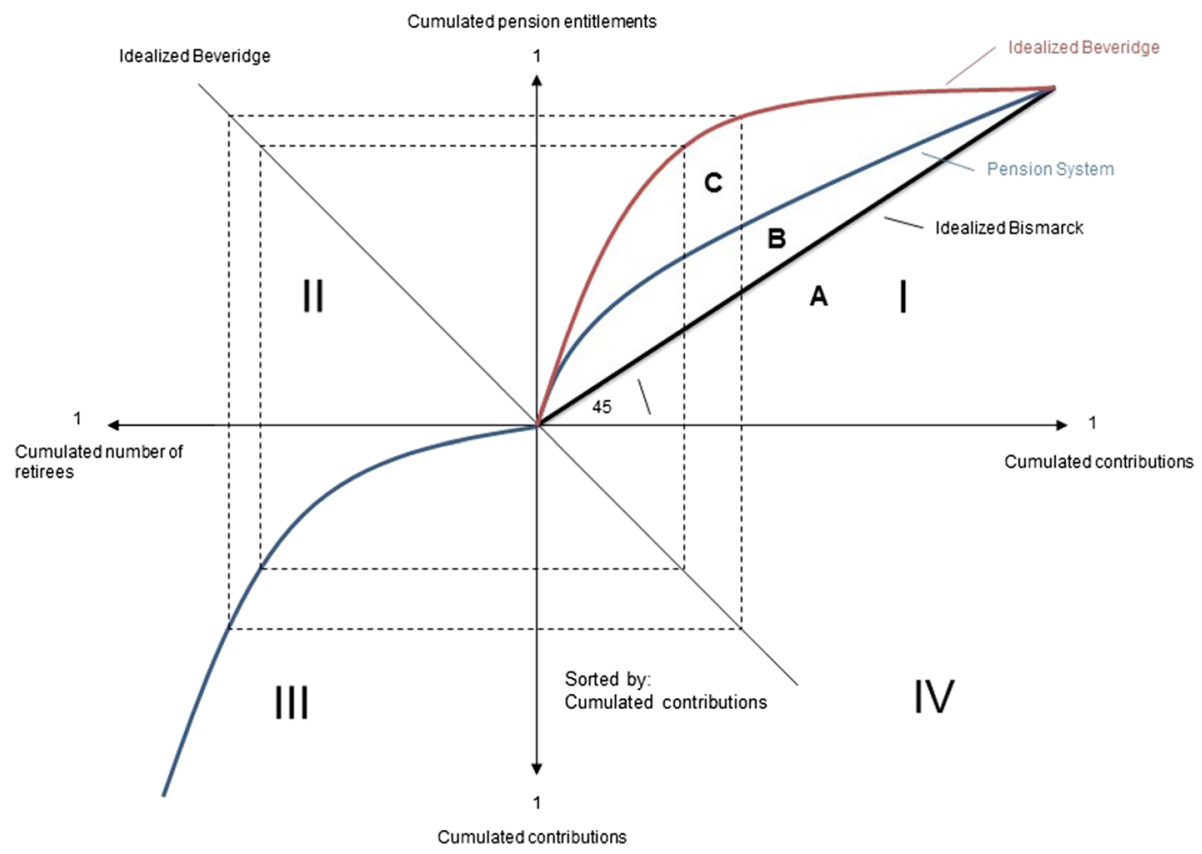

Fig. 1 Graphical derivation of index $R$

Values greater than 1 are feasible if the underlying pension system is extremely generous, such that $P S(e)$ intersects or lies above $\operatorname{Bev}(e)$. This is also possible if all retirees have contributed only very small amounts such that $\operatorname{Bev}(e)$ is not sufficient to provide basic welfare. ${ }^{20}$ Another special case would be a perfectly equal distribution of paid contributions. This could occur if the underlying pension scheme would not utilize a proportional contribution rate but a flat and equal contribution. In this case we would receive $\operatorname{Bev}(e)=\operatorname{Bis}(e)$ and the index would not be defined, since the denominator would be 0 . Nevertheless, those special cases are relatively unlikely, since those cases would systematically violate the principle of equivalence, which is not likely if we apply the index to real-world pension systems.

Figure 1 shows how to graphically derive index $R$. Using normalized values for a given sample population of retirees, quadrant I relates individual contributions to pension entitlements. The bisector of quadrant I represents the idealized Bismarckian pension system as defined in Eq. (9). In this benchmark system, pension entitlements depend only on individual contributions and strictly adhere to the principle of equivalence.

Equation (8), the Beveridgean benchmark, is derived via quadrants II-IV. Quadrant III represents the distribution of individual contributions with the horizontal axis depicting the number of retirees, ordered and normalized by contributions. The resulting curve represents the composition of the underlying sample population, i.e., the income distribution and the contribution scheme prior to retirement. If contributions are determined by proportional contribution rates, a curve with a very sharp increase in the upper parts of the retiree

\footnotetext{
${ }^{20}$ Similarly, an immigration wave of elderly people who never contributed to the pension system but receive at least a minimum pension could trigger such an effect.
} 
distribution would therefore be a representation of unevenly distributed incomes. The distribution of quadrant III, which is the sole determinant for the Beveridgean benchmark, now has to be transferred to quadrant I to receive the second benchmark distribution. This is achieved via quadrants II and IV. Contributions are mirrored to quadrant I via quadrant IV, while the required pension entitlements are determined and transferred via quadrant II. The second quadrant relates the accumulated number of retirees to accumulated pension entitlements. Therefore, the bisection of this quadrant represents the idealized Beveridge system of Eq. (8). Here, every sample member receives exactly the same pension entitlements.

After constructing the two benchmark distributions, the actual pension entitlements of the retirees can be calculated to construct the curve that represents the pension system in quadrant I. The purpose of index $R$ is to measure how strongly the curve of the pension system is trending towards one of the two benchmarks. Using Fig. 1, Eqs. (8)-(10) can be represented as the areas of quadrant I:

$$
\begin{array}{cc}
\text { Beveridge : } & A+B+C \\
\text { Bismarck : } & A \\
\text { Pension System : } & A+B
\end{array}
$$

Therefore, Eq. (11) can be interpreted as:

$$
R:=\frac{A+B-A}{A+B+C-A}=\frac{B}{B+C} .
$$

This representation is reminiscent of the graphical derivation of the Gini coefficient. It is important to note, however, that the size of $C$ differs depending on the underlying pension system. Direct comparisons of pension systems of different countries cannot easily be conducted.

\section{Empirical application using German contribution records}

\subsection{The German old-age pension system}

The German statutory pension plan (Federal Pension Insurance GRV) is designed as an earnings-related PAYG scheme based on the principle of equivalence. Regular old-age pensions can be claimed at the statutory retirement age which is, as of now, gradually increasing from age 65 to 67 for individuals born after 1964. Furthermore, a minimum of 5 years of paid contributions is required to be entitled for an old-age pension.

Equivalence is achieved by income-related earnings points. Paying exactly the contribution of an average earner (relative to all contributors in a certain year) yields one full earnings point. Contributions by earners above and below the average yield the corresponding fraction or multiple of an earnings point; e.g., earning and contributing half the average will result in 0.5 earnings points. The sum of earnings points forms the basis for calculating pension claims at the time of retirement. This design could be characterized as a pure Bismarckian pension system if claims would indeed depend exclusively on one's own 
contributions. However, additional non-earnings-related pension points can be awarded. These are primarily the ones listed in Table 1.

Earnings points can also be deducted in the case of a settlement of pension entitlements following a divorce or because pension claims exist against other countries' pension systems (Vertragsrenten). The extent of those additional benefits (and deductions) determines the level of intra-generational redistribution of the German statutory pension plan. At retirement, earnings points are multiplied by the so-called pension value, resulting in the final pension entitlement (in euros). ${ }^{21}$ The pension value is the same for all pensioners and is adjusted on a yearly basis according to the growth rate of gross wages and some demographics-related parameters. ${ }^{22}$

\subsection{Data}

We use data on new entries into the pension system (Versichertenrentenzugang) from 2007 to 2015 provided by the Research Data Centre of the German Pension Insurance. The Research Data Centre offers cross-sectional and longitudinal datasets on individuals who are insured in the Federal Pension Insurance on an annual basis. Our data on new retirees represent a $10 \%$ sample of individuals who enter retirement in a given year and provide sociodemographic and pension-specific information. In 2015, this dataset compromised about 130 variables for approximately 105,000 individuals. $^{23}$

\subsection{Measuring intra-generational redistribution for new German pensioners}

In the following section, we will apply our index $R$ to data from pensioners who entered retirement in a certain year. We focus on new retirees, because changes in pension system parameters are usually phased in, and therefore the effect is most pronounced for new retirees. This is especially true for changes in intra-generational redistribution, as they are usually not introduced in a backdated way and thus start to affect only the newest cohort. Technically, by looking only at new entries into retirement we reduce the risk that our measure accidentally includes inter-generational redistribution. Furthermore, we focus on those new retirees that claim a regular old-age pension, which is the standard pension claim in the German Federal Pension Insurance. We do so to avoid distortions that may result from mixing regular, early retirement and invalidity pensions. ${ }^{24}$

Following the rules of the GRV, we use two primary reference values of the earnings points system. Our measure of paid contributions is the sum of own earnings points $(O E P)$ that an individual accumulates during her contribution period. Own earnings points can only be obtained by being employed and paying contributions; therefore, they are a direct and proportional proxy of contributions paid $e_{i}$. As described above, one year of

\footnotetext{
21 The so-called pension formula also adjusts earnings points with an access factor that measures early/late retirement, and with a pension type factor that applies to, e.g., widows' pensions. In the case of a regular old-age pension (Regelaltersrente), this factor is 1.

22 For more detailed information about the German pension system see, e.g., Börsch-Supan and Wilke (2004).

${ }^{23}$ For more detailed information on the scope of the data, see Himmelreicher (2005).

24 Early retirement generally results in a reduced pension entitlement depending on the years left until statutory retirement age. Invalidity pensions are paid depending on the level of reduced earnings capacity in the years before statutory retirement age.
} 
employment yields a certain number of earnings points, which result from a comparison of one's own wage and the average gross income. Therefore, the resulting number of $O E P \mathrm{~s}$ when entering retirement in $t$ is given by

$$
O E P=\sum_{l=1}^{t} \frac{Y_{l}}{\bar{Y}_{l}}
$$

with $Y_{l}$ being personal income in year $l$ and $\bar{Y}$ being the mean income of all contributors. ${ }^{25}$ Note that this way of calculating earnings points reflects the idea of function $h(\cdot)$ in Eq. (3). In a pure Bismarckian pension system, these points would be the relevant basis for pension benefits.

Regarding pension entitlements, we use the sum of personal earnings points $P E P$ which is the final sum of earnings points after adjustments. Personal earnings points are defined as:

$$
P E P=\underbrace{O E P}_{\text {own contributions }}+\underbrace{\operatorname{additional~} E P+\text { deducted } E P}_{\text {not depending on own contributions }}
$$

Since we are looking at regular old-age pensions, personal earnings points are the main factor determining an individual's pension entitlement. There are regional differences due to German reunification, but these differences only affect how the sum of personal earnings points is valued, or they have already been corrected during the contribution period.

Figure 2 presents the results for new pensioners who entered retirement in 2015 and received benefits for the first time. The actual pension system (PS) as defined in Eq. (10) is represented by the GRV curve.

According to the Beveridge curve, the majority of contributions were located in the lower $40 \%$ of the distribution of own earnings points. In terms of personal entitlements, the GRV curve indicates redistribution that is especially pronounced in the lower half of the distribution of own contributions. Since our analysis is based on sample data of

Fig. 2 New retirees in 2015

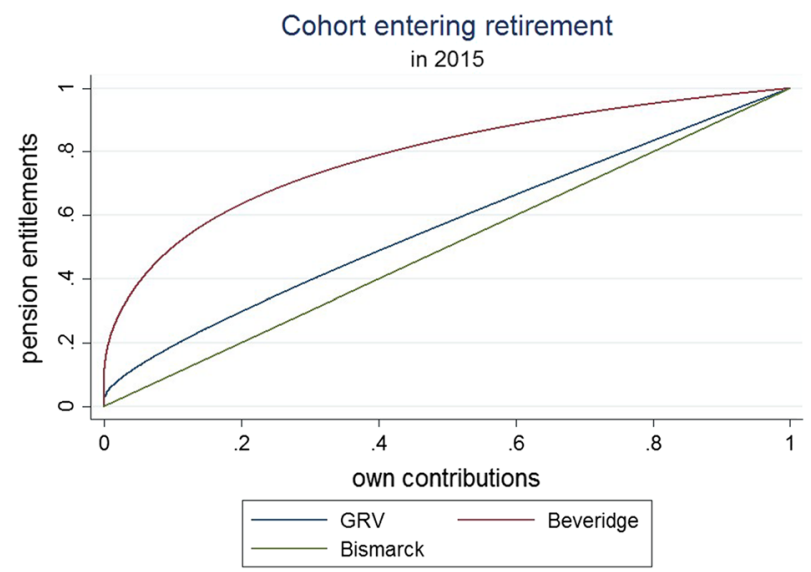

${ }_{25}$ Additionally, contributable income $Y$ and therefore $O E P$ per year are capped by a contribution ceiling. 
contributions and pension benefits rather than on full data, we calculated the respective standard errors for our average values of $\operatorname{Bev}(e)$ and $P S(e)$, based on 500 bootstrap iterations of a $75 \%$ subsample of our data (following Dardanoni \& Forcina, 1999; Davidson, 2009). All standard errors turned out to be lower than 0.00005 , so for the sake of readability we do not report them here. ${ }^{26}$ Our calculations yield $\operatorname{Bev}(e)=0.7857$ and $P S(e)=0.5648$; together with $\operatorname{Bis}(e)=0.5000$ (see Eq. (11)), we get:

$$
R=\frac{0.5648-0.5000}{0.7857-0.5000}=0.2266 \text {. }
$$

Figure 3 shows the underlying curves for male and female new entries into retirement. It is striking to see that the GRV curve is much closer to a Bismarckian system for men than for women. Furthermore, we find differences in the underlying distribution of individual contributions. The Beveridge curve for women concentrates more mass in the lower quantiles of the distribution of individual contributions, while male contributions are more evenly distributed.

Compared to the value of $R$ for all retirees, we get an $R$ of 0.0421 for men only and 0.3566 for women only. ${ }^{27}$ That is, our index $R$ is much smaller for men than for women, which indicates that-measured in terms of individual contributions-men receive significantly fewer additional entitlements (beyond the Bismarckian line of own contributions in Fig. 3) than women. This is not surprising because women are more likely to gain additional earnings points that are detached from individual contributions (e.g., for raising

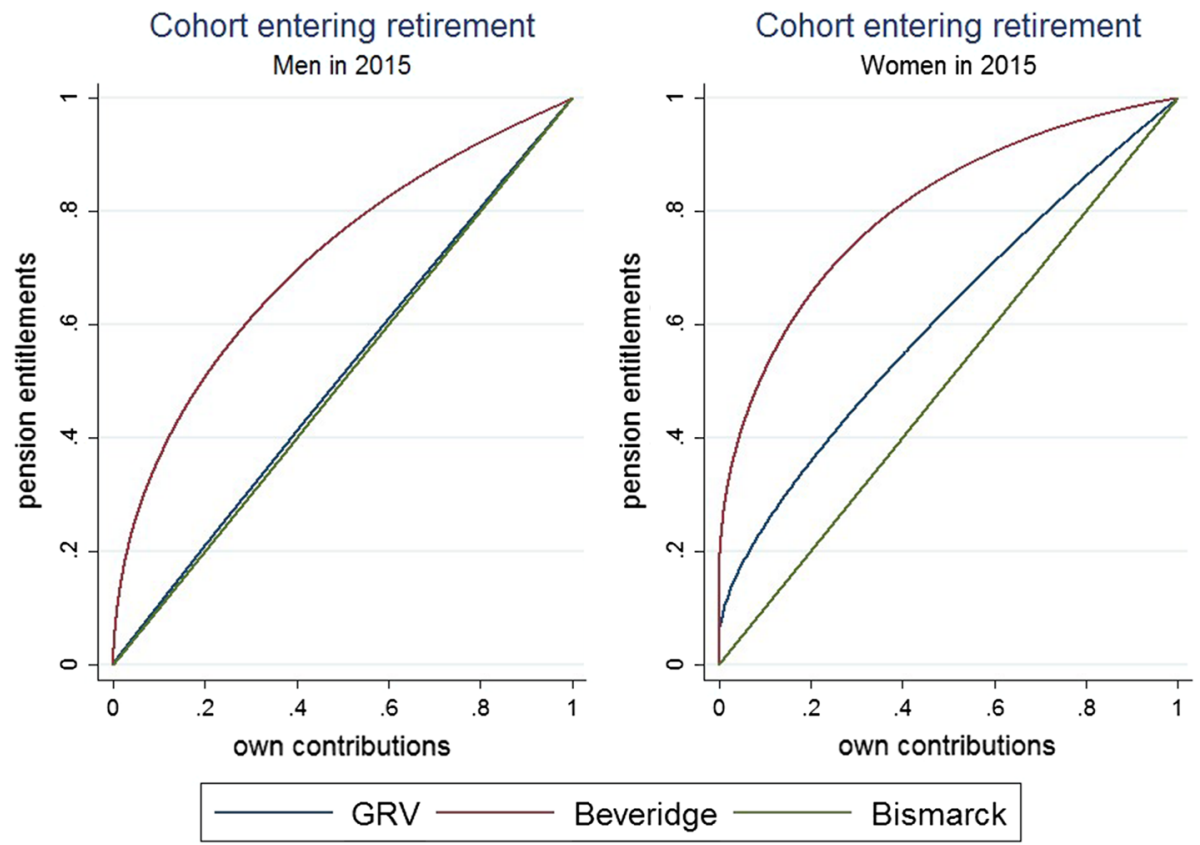

Fig. 3 New retirees in 2015 by sex

\footnotetext{
${ }^{26}$ We get similar results for averages and standard errors with subsamples of different size and more bootstrap iterations.

27 While $\operatorname{Bev}(e)$ is 0.7114 for men only and 0.8042 for women only, $P S(e)$ for men only is 0.5089 and 0.6085 for women only.
} 
children). In addition, they are-on average-more likely to receive bonus points in case of divorce.

Note that the total value for $R$ measures the effect of the whole population with both males and females being part of the distribution of own earnings points and pension entitlements. Therefore, the total value of $R$ should not be interpreted as a function of the values for men and women.

Since data on new retirees is available from 2007 to 2015, we can also calculate $R$ for several cohorts to explore time trends. Figure 4 depicts the development over time for the overall population as well as gender-specific developments.

For the total populations, index $R$ exhibits a slightly increasing trend between 2010 and 2013 from 0.1439 to 0.1614 and a significant increase to 0.2238 in 2014 . For men, the index remains nearly constant over time. In contrast, the index decreased for women prior to 2014 (from 0.3455 in 2007 to 0.2521 in 2013), which was primarily driven by a significant reduction of redistributional entitlements. From 2007 to 2013, received entitlements, which represent the numerator of $R$, dropped from 0.0920 to 0.0692 , a decrease of approximately $25 \%$. At the same time, individual female contributions, measured by $\operatorname{Bev}(e)$, increased from 0.7622 to 0.7747 , i.e., by approximately $1 \%$. Taken together, women showed a tendency for reduced dependency on redistributional pension claims and an increased dependency on own contributions prior to 2014. This tendency might still be valid after 2014. Data on future retirees will show if this general downward trend persists.

Independent of this general trend, we observe a significant upward shift in the value of $R$ in 2014, indicating a massive change in the degree of intra-generational redistribution toward women in the GRV. Actually, $R$ for women only increased from 0.2521 in 2013 to 0.3607 in 2014, thereby leading to the previously mentioned increase in the overall $R$ from 0.1614 to 0.2238 . This shift can be explained by a recent legislative reform-Gesetz über Leistungsverbesserungen in der gesetzlichen Rentenversicherung (enacted in June 2014)that doubled the number of obtainable earnings points resulting from childcare. More specifically, the GRV awards non-earnings-related pension points for raising children. Before the reform, mothers received one earnings point per child born before 1992 and three earnings points for children born after 1992. One pension point means that a mother is awarded the equivalent of having been employed for 1 year, thereby earning the average income.

The ruling grand coalition in Germany considered this unfair for mothers with older children and therefore increased earnings points from one to two for any child born before 1992. The reform was designed in a way that even mothers close to retirement could benefit from the more generous benefits, which means that our analysis ought to capture the reform by driving up $R$ for women, but not for men. ${ }^{28}$ In fact, most women entering retirement in recent years received earnings points for childcare periods before 1992, since it is extremely unlikely that they had a child born after 1992. In order to measure the importance of the reform, we take the difference between $R$ including all pension entitlements and $R$ without the additional benefits for childcare periods in question.

Note that — unlike the analysis of different cohorts of pensioners-such comparison for the same person under different types of legislation may theoretically be biased due to reordering effects. However, the construction of our measure $R$ ensures that this theoretically possible bias is nearly nonexistent empirically. Since own contributions are always fixed within our analysis, reordering can only take place between cases with equal values of own

\footnotetext{
${ }^{28}$ It has to be noted that childcare periods are awarded to the mother by default. Fathers can apply to receive these periods instead, but in practice, this rarely happens.
} 
Fig. 4 Index values over time

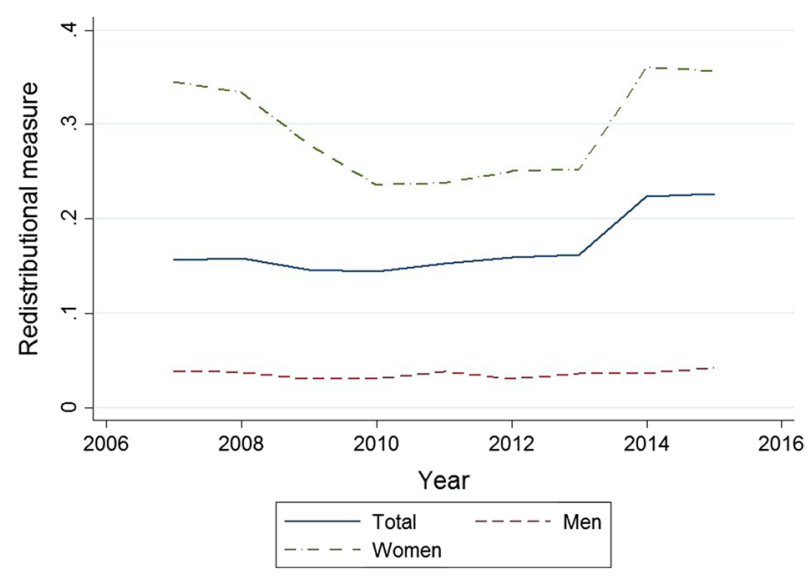

Fig. 5 Results with and without

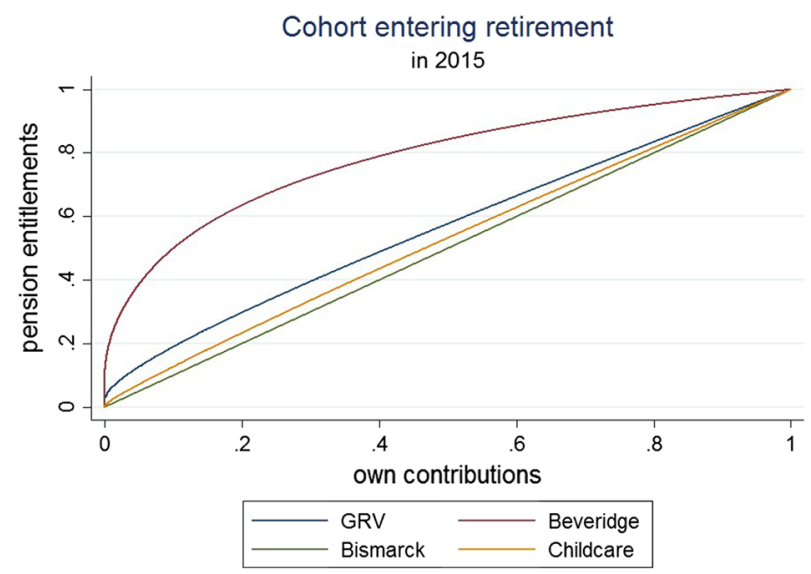
childcare

contributions but with different values of pension entitlements. Our analysis shows that reordering affects our measure for $R$ only in the seventh decimal place.

Figure 5 shows that childcare contributes substantially to the level of intra-generational redistribution in the GRV. If we remove childcare-related pension entitlements, retirees in 2015 are significantly closer to the Bismarckian benchmark line: $R$ drops from 0.2266 including all pension entitlements to 0.0876 without additional benefits for childcare periods. Not surprisingly, this type of additional benefit is of much greater importance for women. While the difference in $R$ for women is 0.2398 , it is 0.0019 for men, which is, albeit statistically significant, nearly nonexistent.

Looking at the development over time, the reform of claimable childcare periods is clearly visible in Fig. 6. It depicts the differences in $R$ due to childcare periods. The difference for women increases significantly in 2014, while changes for men are marginal. The difference in the female $R$ increases by 13 percentage points (from 0.1222 in 2013 to 0.2498 in 2014).

If we take into account that the overall female index value in these years increased by only 11 percentage points (from 0.2521 to 0.3607 ), we can conclude that without the 
Fig. 6 Differences in the redistributional effects of childcare over time

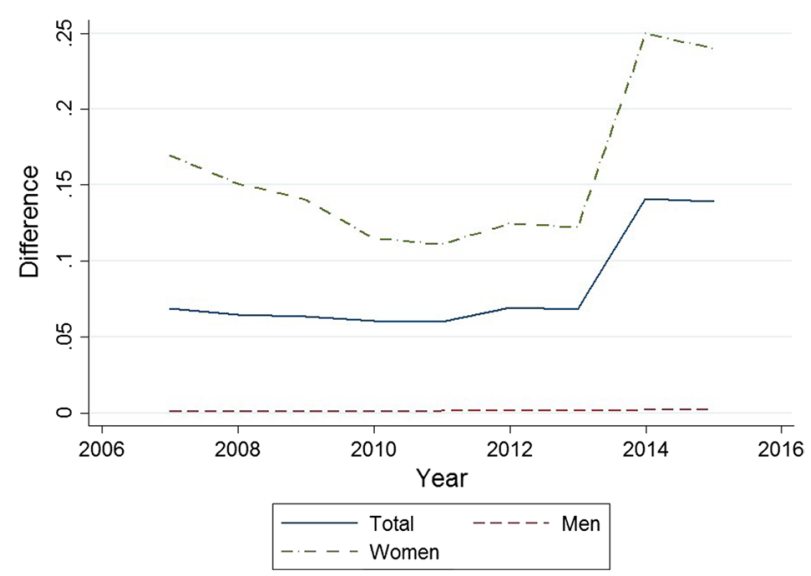

reform, female intra-generational redistribution would have followed the decreasing trend of previous years. These findings demonstrate that not only is $R$ able to quantify changes in intra-generational redistribution due to reformed legislation, but it also shows how different subgroups contribute to these shifts in redistribution.

\section{Concluding remarks}

Recent and future demographic change, caused by low fertility and rising longevity, leave societies with PAYG pension schemes facing an increasing need for reform, especially in their public pension systems. Reforming a pension scheme might require a deviation from the current level of intra-generational redistribution, which has - up to that point in timealso represented an accepted social consensus. This deviation will be of crucial importance for the feasibility of reforms of established pension schemes, as the new level of redistribution must also be widely accepted in society and have sufficient democratic support by the voters.

The purpose of this paper was to introduce a novel index that enables us to measure intra-generational redistribution in a PAYG pension system, where this redistribution results from parametric policy changes affecting the acquisition of entitlements already during work life. Existing measures, like the index of non-contributiveness or the index of progressivity, are limited by setting different generations into relation, while information on individual contributions and resulting pension claims are not taken into account. Extending existing concepts for measuring inequality and the progressiveness of tax systems, we derive an index that relates paid contributions and resulting pension entitlements to a benchmark that rests on a ratio of two hypothetical distributions, an idealized Beveridge system and an idealized Bismarck system. Therefore, this index does not depend on information on younger contributors. It utilizes the complete distribution of pension claims and own contributions rather than relying only on certain quintiles or moments. Our specification also allows us to compare intra-generational redistribution across different cohorts, as well as for different subgroups within a generation.

Applying our index to contribution records of newly retired Germans, we are able to measure the development of intra-generational redistribution across different cohorts. We 
can show that the index is able to measure the effects of legislative changes in intra-generational redistribution. We find that the index stays nearly constant before the year 2014, with only a slight reduction over time for women. In 2015, the index scores a value of intragenerational redistribution of 0.2266 . In 2014, the index increases significantly, which can be mainly attributed to a singular regulatory change in the German public pension system: the extension of claimable childcare periods for children born prior to 1992. This is of special interest, since the main arguments for this legislative reform put forward by its proponents related to inter- rather than intra-generational justice. However, our analysis indicates a strong intra-generationally redistributive effect of this reform. In fact, our decomposition analysis reveals significant differences between men and women before and, even more so, after the reform. The level of intra-generational redistribution for male retirees closely resembles the Bismarckian principle of equivalence, while women's benefits are considerably less Bismarckian in nature.

Our approach allows us to utilize high-quality micro-data in order to derive very precisely the redistributive properties of pension systems. This precision comes at the price that our approach does not allow us to directly compare pension schemes of different countries as would be possible using, e.g., LIS data (which has other downsides instead). It would nevertheless be instructive to conduct analyses similar to ours for other countries, in which similar data may be available. For instance, there is register-based pension data in Sweden (cf. Edin \& Fredriksson, 2000) and Denmark (cf. Hjollund et al., 2007). Moreover, even in cases where such real-world data are unavailable, our index could be applied to simulated data (cf., e.g., Fredriksen \& Stølen, 2017, for a related approach). ${ }^{29}$

Future research should also include an analysis of recent trends in intra-generational redistribution in these countries and should investigate the degree to which these trends have been the result of policy changes. Similar to the German reform of claimable childcare periods, the legislative importance of intra-generational redistribution in other countries' policy reforms could also be investigated from an analogous political-economic perspective. In this context (and with reference to the second dimension of intra-generational redistribution mentioned in Sect. 2), it could be of particular interest to also include the role of life expectancy differentials between different groups in society as well as their effect on pension policies chosen by, e.g., the median voter. Given the availability of consistent data, such an analysis would be straightforward to implement within the concept of the index proposed here.

Another interesting avenue of research would be to explore the welfare properties of our index in more detail. More specifically, the question that could be asked is whether the transfer principle has any ethical meaning in the context of intra-generational redistribution, such that welfare rankings from our index may be obtained. Such welfare rankings would then have to assume that people have, e.g., a preference for the equivalence principle rather than a preference for the equality of pensions. Given that experimental evidence by Krieger et al. (2020) points to a preference for intermediate levels of intra-generational redistribution, careful further investigation is needed to answer this question.

Acknowledgements The authors would like to thank three anonymous reviewers, the journal's editor William F. Shughart II, Carl Hase, the participants of the annual conference of the Verein für Socialpolitik (Freiburg 2018), the Public Economics Research Seminar (Munich 2018), the 7th World Congress of the

\footnotetext{
${ }^{29}$ For instance, the micro-simulation EUROMOD could possibly be used here, as it allows us to calculate, based on EU-SILC, the contributions and benefits from various programs and simulate reforms.
} 
International Microsimulation Association (Galway 2019), the CESifo Area Conference on Employment and Social Protection (Munich 2019), as well as the research seminars at the Universities of Strasbourg and Basel for their most helpful comments and discussions.

Funding Open Access funding enabled and organized by Projekt DEAL.

\section{Declarations}

Conflict of interest The authors declare that they have no conflict of interest.

Open Access This article is licensed under a Creative Commons Attribution 4.0 International License, which permits use, sharing, adaptation, distribution and reproduction in any medium or format, as long as you give appropriate credit to the original author(s) and the source, provide a link to the Creative Commons licence, and indicate if changes were made. The images or other third party material in this article are included in the article's Creative Commons licence, unless indicated otherwise in a credit line to the material. If material is not included in the article's Creative Commons licence and your intended use is not permitted by statutory regulation or exceeds the permitted use, you will need to obtain permission directly from the copyright holder. To view a copy of this licence, visit http://creativecommons.org/licenses/by/4.0/.

\section{References}

Auerbach, A. J., \& Kotlikoff, L. J. (1987). Dynamic fiscal policy. Cambridge University Press.

Bagchi, S. (2019). Differential mortality and the progressivity of social security. Journal of Public Economics, $177,104044$.

Bishnu, M., Guo, N. L., \& Kumru, C. S. (2019). Social security with differential mortality. Journal of Macroeconomics, 62, 103077.

Bommier, A., Leroux, M.-L., \& Lozachmeur, J.-M. (2011). On the public economics of annuities with differential mortality. Journal of Public Economics, 95, 612-623.

Börsch-Supan, A., \& Reil-Held, A. (2001). How much is transfer and how much is insurance in a pay-asyou-go system? The German case. Scandinavian Journal of Economics, 103(3), 505-524.

Börsch-Supan, A., \& Wilke, C. B. (2004). The German public pension system: How it was, how it will be. Technical report, National Bureau of Economic Research.

Boskin, M. J. (1986). Too many promises: The uncertain future of Social Security. Dow Jones-Irwin.

Brown, J., Coronado, J. L., \& Fullerton D. (2006). The progressivity of social security. NBER Papers on Retirement Research Center Projects, NB06, 10.

Browning, E. K. (1975). Why the social insurance budget is too large in a democracy. Economic Inquiry, 13(3), 373-388.

Casamatta, G., Cremer, H., \& Pestieau, P. (2000a). The political economy of social security. Scandinavian Journal of Economics, 102(3), 503-522.

Casamatta, G., Cremer, H., \& Pestieau, P. (2000b). Political sustainability and the design of social insurance. Journal of Public Economics, 75(3), 341-364.

Conde-Ruiz, J. I., \& Profeta, P. (2007). The redistributive design of social security systems. Economic Journal, 117, 686-712.

Coronado, J. L., Fullerton, D., \& Glass, T. (2011). The progressivity of social security. BE Journal of Economic Analysis and Policy, 11(1), Article 70.

Cremer, H., \& Pestieau, P. (2003). Social insurance competition between Bismarck and Beveridge. Journal of Urban Economics, 54(1), 181-196.

Cutler, D., Deaton, A., \& Lleras-Muney, A. (2006). The determinants of mortality. Journal of Economic Perspectives, 20(3), 97-120.

Dardanoni, V., \& Forcina, A. (1999). Inference for Lorenz curve orderings. The Econometrics Journal, 2(1), 49-75.

Davidson, R. (2009). Reliable inference for the Gini index. Journal of Econometrics, 150(1), 30-40.

Edin, P., \& Fredriksson, P. (2000). LINDA—Longitudinal individual data for Sweden. Uppsala University Working Paper No. 2000:19.

Fredriksen, D., \& Stølen, N. (2017). Lifetime pension benefits relative to lifetime contributions. International Journal of Microsimulation, 10(2), 177-207. 
Goda, G. S., Shoven, J. B., \& Slavov, S. N. (2011). Differential mortality by income and social security progressivity. In D. A. Wise (Ed.), Explorations in the economics of aging (pp. 189-204). University of Chicago Press.

Himmelreicher, R. (2005). Analysepotential des Scientific Use Files Versichertenrentenzugang. DRV-Schriften, 55(2005), 38-92.

Hjollund, N., Larsen, F., \& Andersen, J. (2007). Register-based follow-up of social benefits and other transfer payments: Accuracy and degree of completeness in a Danish interdepartmental administrative database compared with a population-based survey. Scandinavian Journal of Public Health, 35, 497-502.

Jenkins, S. (1988). Reranking and the analysis of income redistribution. Scottish Journal of Political Economy, 35(1), 65-76.

Kotlikoff, L. J. (1998). Simulating the privatization of social security in general equilibrium. In M. Feldstein (Ed.), Privatizing social security. Chicago: University of Chicago Press.

Kotlikoff, L. J., Smetters, K., \& Walliser, J. (1999). Privatizing social security in the United States-Comparing the options. Review of Economic Dynamics, 2(3), 532-574.

Krieger, T., \& Lange, T. (2012). Education, life expectancy and pension reform. Hacienda Pública Española, 202(3), 31-55.

Krieger, T., Meemann, C., \& Traub, S. (2020). Inequality, life expectancy, and the intragenerational redistribution puzzle: Some experimental evidence. Mimeo.

Krieger, T., \& Ruhose, J. (2013). Honey, I shrunk the kids' benefits-Revisiting intergenerational conflict in OECD countries. Public Choice, 157(1-2), 115-143.

Krieger, T., \& Stöwhase, S. (2009). Diskretionäre rentenpolitische Maßnahmen und die Entwicklung des Rentenwerts in Deutschland 2003-2008. Zeitschrift für Wirtschaftspolitik, 58(1), 36-54.

Krieger, T., \& Traub, S. (2008). Back to bismarck? Shifting preferences for intragenerational redistribution in OECD pension systems. Luxembourg Income Study Working Paper Series No. 485.

Krieger, T., \& Traub, S. (2011). Wie hat sich die intragenerationale Umverteilung in der staatlichen Säule des Rentensystems verändert? Ein internationaler Vergleich auf Basis von LIS-Daten. Jahrbücher für Nationalökonomie und Statistik, 231(2), 266-287.

Krieger, T., \& Traub, S. (2013). The Bismarckian factor: A measure of intra-generational redistribution in international pension systems. Cesifo DICE Report, 11(1), 64-66.

Lambert, P. J., \& Ramos, X. (1997). Horizontal inequity and vertical redistribution. International Tax and Public Finance, 4(1), 25-37.

Lefèbvre, M. (2007). The redistributive effects of pension systems in Europe: A survey of evidence. Luxembourg Income Study Working Paper Series No. 457.

Lefèbvre, M., \& Pestieau, P. (2006). The generosity of the welfare state towards the elderly. Empirica, 33, 351-360.

Marmot, M. (2005). Social determinants of health inequalities. Lancet, 365(9464), 1099-1104.

OECD. (2013). Pensions at a glance 2013: OECD and G20 indicators. OECD Publishing.

OECD. (2019). Pensions at a glance 2019: OECD and G20 indicators. OECD Publishing.

Seidl, C., Pogorelskiy, K., \& Traub, S. (2012). Tax progression in OECD countries: An integrative analysis of tax schedules and income distributions. Springer.

Sjoblom, K. (1985). Voting for social security. Public Choice, 45(3), 225-240.

Stöwhase, S. (2016). Systemimmanente intra-generationelle Umverteilung in der gesetzlichen Rentenversicherung. Wie groß ist die kohortenspezifische Lücke zwischen Beitrags- und Teilhabeäquivalenz? Sozialer Fortschritt, 65(4), 83-89.

Suits, D. (1977). Measurement of tax progressivity. American Economic Review, 67(4), 747-752.

Waldron, H. (2013). Mortality differentials by lifetime earnings decile: Implications for evaluations of proposed social security law changes. Social Security Bulletin, 73(1), 1-37.

Publisher's Note Springer Nature remains neutral with regard to jurisdictional claims in published maps and institutional affiliations. 